\title{
A survey on the stability of mean value points and functional equations involving some special functions
}

\section{SORinel Dumitrescu ${ }^{1}$, Mihai MoneA ${ }^{1}$ and CRistinel Mortici ${ }^{2,3}$}

\section{ABSTRACT.}

The aim of this work is to put together some of the recent and classical results in the theory of stability. In the first part, we recall the results regarding the intermediary points arising from various Mean Value Theorems, then we study the stability of some functional equations involving the gamma and beta functions.

Acknowledgements. The authors would like to thank the reviewers for valuable comments and corrections. The work of Cristinel Mortici was supported by a grant of the Romanian National Authority for Scientific Research, CNCS-UEFISCDI project number PN-II-ID-PCE-2011-3-0087. Cristinel Mortici contributed to this work during his visit at the National Technical University of Athens, Greece, in August 2014.

\section{REFERENCES}

[1] Abramowitz, M. and Stegun, I. A., Handbook of Mathematical Functions with Formulas, Graphs, and Mathematical Tables, New York: Dover, 1972

[2] Agarwal, R. P., Xu, B. and Zhang, W., Stability of functional equations in single variable, J. Math. Anal. Appl., 288 (2003), 852-869

[3] Alimohammady, M. and Sadeghi, A., Stability and common stability for the systems of linear equations and its applications, Math. Sci., 2012 (2012), 6:43

[4] Artin, E., The Gamma Function, in Rosen, Michael (ed.) Exposition by Emil Artin: a selection; History of Mathematics 30, Providence, RI: Amer. Math. Soc. (2006)

[5] Baker, J., The stability of the cosine equation, Proc. Amer. Math. Soc., 80 (1980), 411-416

[6] Baker, J., The stability of certain functional equations, Proc. Amer. Math. Soc., 112 (1991), 729-732

[7] Barnes, E. W., The theory of the double-gamma function, Proc. Roy. Soc. London Ser. A, 196 (1901), 265-388

[8] Barnes, E. W., The theory of the G-function, Quart. J. Math., 31 (1899), 264-314

[9] Das, M., Riedel, T. and Sahoo, P. K., Hyers-Ulam Stability of Flett's Points, Appl. Math. Lett., 16 (2003), 269-271

[10] Eskandani, G. Z. and Rassias, Th. M., Hyers-Ulam-Rassias Stability of Derivations in Proper JCQ*triples, Mediterr. J. Math., 10 (2013), No. 3 , $1391-1400$

[11] Flett, T. M., A mean value theorem, Math. Gazette, 42 (1958), 38-39

[12] Forti, G. L., Hyers-Ulam stability of functional equations in several variables, Aequationes Math., 50 (1995), 143-190

[13] Găvruţă, P., Jung, S.-M. and Li, Y., Hyers-Ulam stability of mean value points, Ann. Funct. Anal., 1 (2010), No. 2, 68-74

[14] Găvruță, P., A generalization of the Hyers-Ulam-Rassias stability of approximately additive mappings, J. Math. Anal. Appl., 184 (194), 431-436

[15] Ger, R., Superstability is not natural, Rocznik Naukowo-Dydaktyczny WSP w Krakowie, Prace Mat., 159 (1993), 109-123

[16] Ger, R. and Šemrl, P., The stability of the exponential equation, Proc. Amer. Math. Soc., 124 (1996), No. 3, 779-787

[17] Hutník, O. and Molnárová, J., On Flett's mean value theorem, Aequat. Math., DOI 10.1007/s00010-014-0311-5

[18] Hyers, D. H. and Ulam, S. M., On the stability of differential expressions, Math. Mag., 28 (1954), 59-64

[19] Hyers, D. H., On the stability of the linear functional equation, Proc. Natl. Acad. Sci. USA, 27 (1941), 222-224

[20] Hyers, D. H., On the stability of minimum points, J. Math. Anal. Appl., 62 (1976), 530-537

[21] Hyers, D. H., On the stability of stationary points, J. Math. Anal. Appl., 36 (1971), 622-626

[22] Hyers, D. H. and Rassias, Th. M., Approximate homomorphisms, Aequationes Math., 44 (1992), 125-153

[23] Jung, S.-M., On the modified Hyers-Ulam-Rassias stability of the functional equation for gamma function, Mathematica (Cluj), 39 (62) (1997), No. 2, 233-237

[24] Jung, S.-M., Hyers-Ulam-Rassias Stability of Functional Equations in Nonlinear Analysis, Springer Optimization and Its Applications Vol. 48, Springer, New York, 2011

[25] Jung, S.-M., Hyers-Ulam stability of Butler-Rassias functional equation, J. Inequal. Appl., 2005 (2005), 41-47

[26] Jung, S.-M. and Chung, B., Remarks on Hyers-Ulam stability of Butler-Rassias functional equation, Dyn. Contin. Discrete Impuls. Syst. Ser. A Math. Anal., 13 (2006), No. 2, 193-197

[27] Jung, S.-M., Rassias, M. Th. and Mortici, C., On a functional equation of trigonometric type, Appl. Math. Comp. (2015), in press, DOI: 10.1016/j.amc.2014.12.019

[28] Jung, S.-M., Hyers-Ulam stability of zeros of polynomials, Appl. Math. Lett. 24 (2011), No. 8, 1322-1325

[29] Jung, S.-M., Hyers-Ulam stability of linear partial differential equations of first order, Appl. Math. Lett., 22 (2009), Issue 1, 70-74

[30] Jung, S.-M. and Sahoo, P. K., Hyers-Ulam-Rassias Stability of an Equation of Davison, J. Math. Anal. Appl., 238 (1999), Issue 1, 297-304

[31] Kairies, H.-H., Die Gammafunktion als stetige Lösung eines Systems von Gauss-Funktionalgleichungen, Resultate Math., 26 (1994), $306-315$

[32] Kim, G. H., On the stability of generalized gamma functional equation, Intern. J. Math. \& Math. Sci., 23 (2000), No. 8, 513-520

[33] Kim, G. H. and Lee, Y. W., The stability of the generalized form for the gamma functional equation, Comm. Korean Math. Soc., 15 (2000), No. 1, $45-50$

[34] Kim, G. H., On the Hyers-Ulam-Rassias stability of functional equations in n-variables, J. Math. Anal. Appl., 299 (2004), 375-391

[35] Kim, G. H. and Lee, Y. W., On the stability of a beta type functional equations, J. Appl. Math. \& Comp., 14 (2004), No. 1-2, 429-445

[36] Kim, G. H., On the stability of functional equations in n-variables and its applications, Comm. Korean Math. Soc., 20 (2005), No. 2, 321-338

[37] Kim, G. H., On the stability of the generalized G-type functional equations, Comm. Korean Math. Soc., 20 (2005), No. 1, 93-106 
[38] Kim, H.-M., A result concerning the stability of some difference equations and its applications, Proc. Indian Acad. Sci. (Math. Sci.), 112 (2002), No. 3 , $453-462$

[39] Lee, Y. W. and Choi, B. M., The stability of Cauchy's gamma-beta functional equation, J. Math. Anal. Appl., 299 (2004), 305-313

[40] Lee, Y. W. and Choi, B. M., Stability of a beta-type functional equation with a restricted domain, Comm. Korean Math. Soc., 19 (2004), No. 4, 701-713

[41] Lee, Y. W. and Han, S. Y., Generalized stabilities of Cauchy's gamma-beta functional equation, Honam Math. J., 30 (2008), No. 3, 567-579

[42] Lee, Y. W. and Kim, G. H., Approximate gamma-beta type functions, Nonlin. Anal., 71 (2009), e1567-e1574

[43] Lee, Y. W., Approximate pexiderized gamma-beta type functions, J. Inequal. Appl., 2013, 2013:14

[44] Lee, W., Xu, S. and Ye, F., Hyers Ulam stability of Sahoo Riedel's point, Appl. Math. Lett., 22 (2009), 1649-1652

[45] Molnarova, J., On generalized Flett's mean value theorem, Intern. J. Math. Math. Sci., 2012 (2012), Article ID 574634,7 pages

[46] Mortici, C., Rassias, Th. M and Jung, S.-M., On the stability of a functional equation associated with the Fibonacci numbers, Abstr. Appl. Anal., 2014 (2014), Article ID 546046

[47] Mortici, C., Rassias, Th. M. and Jung, S.-M., The inhomogeneous Euler equation and its Hyers-Ulam stability, Appl. Math. Lett., 40 (2015), 23-28

[48] Mortici, C., Rassias, Th. M. and Jung, S.-M., On the Hyers-Ulam stability of $\varphi(x)+a x+b=0$ and its applications, Ciencia e Tecnica, 29 (2014), No. 8, 285-294

[49] Mortici, C., Ramanujan formula for the generalized Stirling approximation, Appl. Math. Comp., 217 (2010), No. 6, 2579-2585

[50] Mortici, C., New approximation formulas for evaluating the ratio of gamma functions, Math. Comp. Modelling, 52 (2010), No. 1-2, 425-433

[51] Mortici, C., Estimating gamma function by digamma function, Math. Comp. Modelling, 52 (2010), No. 5-6, 942-946

[52] Mortici, C., A continued fraction approximation of the gamma function, J. Math. Anal. Appl., 402 (2013), No. 2, 405-410

[53] Park, C., Azadi, K. H. and Rassias, Th. M., Hyers-Ulam-Rassias stability of the additive-quadratic mappings in non-Archimedean Banach spaces, J. Inequal. Appl., 2012, 2012:174

[54] Pawlikowska, I., Stability of $n$-th order Flett's points and Lagrange's points, Sarajevo J. Math., 2 (2006), No. 1, 41-48

[55] Pawlikowska, I., An extension of a theorem of Flett, Demonstr. Math., 32 (1999), 281-286

[56] Peter, I. R. and Popa, D., Stability of points in mean value theorems, Publ. Math. Debrecen, 83 (2013), No. 3, 1-10

[57] Pop, M. S., Asupra unei teoreme de medie a lui Flett, Lucr. Semin. Creativ. Mat., 3 (1993-1994), 79-88 (in Romanian)

[58] Pop, M. S. and Kovacs, G., Generalizari ale unei formule de medie, Lucr. Semin. Creativ. Mat., 3 (1994-1995), 119-126 (in Romanian)

[59] Rassias, Th. M., On the stability of the linear mapping in Banach spaces, Proc. Amer. Math. Soc., 72 (1978), No. 2, 297-300

[60] Rezaei, H., Jung, S.-M. and Rassias, Th. M., Laplace transform and Hyers-Ulam stability of linear differential equations, J. Math. Anal. Appl., 403 (2013), No. 1, 244-251

[61] Rus, I. A., Remarks on Ulam stability of the operatorial equations, Fixed Point Theory, 10 (2009), No. 2, 305-320

[62] Sahoo, P. K. and Riedel, T., Mean Value Theorems and Functional Equations, World Scientific, New Jersey, 1998

[63] Ulam, S. M., A Collection of Mathematical Problems, Interscience, New York 1960, Problems in Modern Mathematics, Science Editions, Wiley, (1964)

[64] Wang, Z., Dong, X., Rassias, Th. M. and Jung, S.-M., Stability of zeros of power series equations, Bull. Korean Math. Soc., 51(2014), No. 1, 77-82

[65] Youssef, M., Elhoucien, E. and Rassias, Th. M., On the Hyers-Ulam stability of the quadratic and Jensen functional equations on a restricted domain, Nonlin. Fct. Anal. Appl., 15 (2010), No. 4 , 647-655

${ }^{1}$ Department of mathematics

Ph. D. Student, University Politehnica of Bucharest

SPlaiUl IndePENDENŢEI 313, Bucharest, Romania

E-mail address: sorineldumitresculyahoo.com

${ }^{1}$ Department of mathematics

Ph. D. Student, University Politehnica of Bucharest

SPLAIUl INDEPENDENŢEI 313, BUCHAREST, ROMANIA

E-mail address: mihaimonea@yahoo.com

2 DePartment OF MATHEMATICS

VALAHIA UNIVERSITY OF TÂRGOVIŞTE

BD. UNIRII 18, 130082 TÂRGOVIŞTE, ROMANIA

3 Department of mathematics

ACADEMY OF THE ROMANIAN SCIENTISTS

SPLAIUl INDEPENDENŢEI 54, 050094 BUCHAREST, ROMANIA

E-mail address: cristinel.morticiehotmail.com 